\title{
Basophil CD203c Levels Are Increased at Baseline and Can Be Used to Monitor Omalizumab Treatment in Subjects with Nut Allergy
}

\author{
Yael Gernez ${ }^{a, b}$ Rabindra Tirouvanziam ${ }^{a, b}$ Grace Yu ${ }^{a}$ Eliver E.B. Ghosn ${ }^{b}$ \\ Neha Reshamwala ${ }^{a}$ Tammie Nguyen ${ }^{a}$ Mindy Tsaic Stephen J. Galli ${ }^{c}$ \\ Leonard A. Herzenberg $^{b}$ Leonore A. Herzenberg ${ }^{b}$ Kari C. Nadeau ${ }^{a}$ \\ Departments of a Pediatrics, ${ }^{b}$ Genetics and ${ }^{c}$ Pathology, Stanford University School of Medicine, Stanford, Calif., USA
}

\section{Key Words}

Anaphylaxis $\cdot$ Atopic $\cdot$ CD203c $\cdot$ Cockroach allergen $\cdot$

Flow cytometry $\cdot$ Human basophils $\cdot$ Omalizumab $\cdot$

Peanut allergy $\cdot$ Tree nut allergy

\begin{abstract}
Rationale: Basophils contribute to anaphylaxis and allergies. We examined the utility of assessing basophil-associated surface antigens (CD11b/CD63/CD123/CD203c/CD294) in characterizing and monitoring subjects with nut allergy. Methods: We used flow cytometry to analyze basophils at baseline (without any activation) and after ex vivo stimulation of whole blood by addition of nut or other allergens for 2 , 10, and $30 \mathrm{~min}$. We also evaluated whether basophil expression of CD11b/CD63/CD123/CD203c/CD294 was altered in subjects treated with anti-IgE monoclonal antibody (omalizumab) to reduce plasma levels of IgE. Results: We demonstrate that basophil CD203c levels are increased at baseline in subjects with nut allergy compared to healthy controls (13 subjects in each group, $p<0.0001$ ). Furthermore, we confirm that significantly increased expression of CD203c occurs on subject basophils when stimulated with the allergen to which the subject is sensitive and can be detected rapidly (10 min of stimulation, $\mathrm{n}=11, \mathrm{p}<0.0008$ ). In 5 subjects with severe peanut allergy, basophil CD203c expres-
\end{abstract}

\section{KARGER}

Fax +41613061234 E-Mail karger@karger.ch www.karger.com

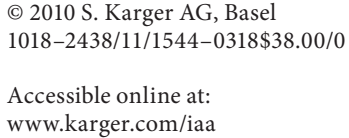

sion following stimulation with peanut allergen was significantly decreased $(p<0.05)$ after 4 and 8 weeks of omalizumab treatment but returned toward pretreatment levels after treatment cessation. Conclusions: Subjects with nut allergy show an increase of basophil CD203c levels at baseline and following rapid ex vivo stimulation with nut allergen. Both can be reduced by omalizumab therapy. These results highlight the potential of using basophil CD203c levels for baseline diagnosis and therapeutic monitoring in subjects with nut allergy.

Copyright $\odot 2010$ S. Karger AG, Basel

\section{Introduction}

Nut allergy is one of the most severe clinical presentations of food allergy [1]. Although not every subject with peanut or other food allergies develops near-fatal symptoms when exposed to the offending allergen, most of them, particularly young children, experience restrictions in their quality of life and nutrition [2]. For this reason, objective endpoints reflecting allergic predisposition towards a given allergen are important for the proper

Y.G. and R.T. contributed equally to the studies presented here. 
identification of at-risk subjects. Currently, such endpoints are limited to skin tests and double-blind placebocontrolled food challenges. Both are cumbersome in vivo procedures with significant associated risks, including anaphylaxis [3]. Hence, reliable ex vivo outcome measures are needed for the diagnosis of allergic subjects.

Furthermore, although some allergy reduction therapies show promise $[4,5]$, definitive demonstration of their efficacy has yet to be accomplished. Omalizumab, a humanized monoclonal antibody against IgE, has been used to treat subjects with peanut allergy in a phase II trial [6], and there are currently several clinical trials in progress testing omalizumab for treatment of other food allergies. A combination of efficacy endpoints [7] and reliable ex vivo outcome measures would be beneficial for evaluating treatment responses in these trials [8]. However, no ex vivo outcome measures have as yet proven reliable to track the effectiveness of omalizumab therapy.

Basophils are involved in mediating anaphylaxis and several studies have presented evidence that basophils can be useful in diagnosing allergies [9-11]. Basophil activation, in addition to activation of mast cells and other immune cells, and subsequent production of chemical mediators (such as histamine) can contribute to the initiation of anaphylaxis [12]. Basophils express the surface activation markers CD11b, CD63, CD123, CD203c and CD294, some of which previously have been shown to reflect allergen-dependent activation of basophils ex vivo $[9,13-19]$.

Our studies presented here demonstrate that CD203c expression on blood basophils is a useful ex vivo outcome measure for subjects with nut allergy. First, we show that basophil CD203c levels at baseline (without any ex vivo stimulation) were significantly higher in subjects with nut allergy than in healthy controls. Second, ex vivo allergen stimulation induced an increase in basophil CD203c levels that appears to be specific to the offending allergen for a given donor. Third, we show that basophil CD203c levels at baseline and upon ex vivo allergen stimulation are reduced by omalizumab therapy in subjects with nut allergy and therefore track treatment responses in vivo.

\section{Methods}

\section{Human Subjects}

The study was approved by the Stanford Administrative Panel of Human Subjects in Medical Research. All 16 food-allergic subjects (or parents, for minors) and all healthy controls $(n=13)$ signed informed consent forms before the subjects underwent study procedures. Details regarding the inclusion of subjects in the various parts of the study are available in the online supplementary material (www.karger.com/doi/10.1159/000321824). Clinical nut or apple allergy (specific to peanut: 12; to cashew: 2; to walnut: 1 ; to apple: 1 ; tables 1,2$)$ was diagnosed by clinical history of food allergy reaction, nut-specific IgE $\geq 15 \mathrm{kU}_{\mathrm{A}} / 1$ (ImmunoCAP; Phadia, Uppsala, Sweden) and/or positive skin prick test to nut allergen (tables 1,2), and severity was graded based on published scores of anaphylaxis symptoms, as noted by NowakWegrzyn et al. [20]. Five of the subjects with a history of anaphylactic reaction to peanuts were enrolled in a phase I open-label study of omalizumab (investigator-initiated study, Stanford IND 103, 711). Omalizumab (Genentech/Novartis, South San Francisco, Calif., USA) was dosed as per product insert guidelines based on total IgE levels and the subject's body weight (tables 1,2).

\section{Sample Collection and Processing}

Blood was collected in ethylene diamine tetraacetic acid (EDTA) tubes by venipuncture, centrifuged $\left(400 \mathrm{~g}, 10 \mathrm{~min}, 4^{\circ} \mathrm{C}\right)$, and the leukocyte pellet retained while the plasma was further centrifuged $\left(3,000 \mathrm{~g}\right.$ for $\left.10 \mathrm{~min}, 4^{\circ} \mathrm{C}\right)$ to remove platelets. The blood sample was then reconstituted to its original volume by adding the platelet-free plasma to the pelleted leukocytes. We removed platelets from the plasma to avoid unwanted aggregation and clotting in the course of our 30 -min assay at $37^{\circ} \mathrm{C}$ (see below).

\section{Basophil Stimulation Assay}

Three microliters of phosphate-buffered saline (PBS) or of an allergen extract (peanut, cockroach, cashew, walnut, apple) used clinically for skin testing (Greer, Lenoir, N.C., USA) were added to $200 \mu \mathrm{l}$ of blood (processed as above) and the mixture was incubated for varying times $(2,10$ or $30 \mathrm{~min})$ at $37^{\circ} \mathrm{C}$. The peanut extract contained shelled, uncooked/unsalted Virginia peanuts, which were ground and then treated with acetone to remove fat. The defatted ground peanuts were dried to remove the acetone and sent to the extract laboratory, where they were extracted in Coca's solution at 1:10 w/v, pre-filtered. The incubation was stopped by adding ice-cold PBS-EDTA (EDTA is a calcium chelator that blocks cell activation) [21], and the cells were pelleted by centrifugation $\left(490 \mathrm{~g}, 5 \mathrm{~min}, 4^{\circ} \mathrm{C}\right)$. The supernatant was removed and stored at $-80^{\circ} \mathrm{C}$.

\section{Immunoglobulins}

Total blood IgE levels were measured in all subjects by the Clinical Laboratories at Stanford Hospital and Clinics using a standard Immunocap (Phadia) assay [22]. Free IgE (non-omalizumab bound) to peanut was measured in the subset of 5 subjects with peanut allergy under ongoing omalizumab therapy, according to the method described by Hamilton et al. [23].

\section{Surface Marker Profiling}

For surface staining, 50 to $200 \mu \mathrm{l}$ of blood were stained with the Live/Dead near-infrared viability probe (Invitrogen, Carlsbad, Calif., USA) and several antibodies against surface determinants for $20 \mathrm{~min}$ on ice, in the dark. These antibodies (clone numbers indicated in parentheses) included CD3 (UCHT1), CD11b (VIM12) and CD16 (3G8) from Invitrogen; CD20 (2H7), CD41a (96.2C1), CD56 (B157), CD63 (H5C6), CD66b (G10F5), CD123 (7G3), CD294 (BM16) and HLA-DR (L243) from BD Biosciences 
Table 1. Characteristics of the subjects

\begin{tabular}{|c|c|c|c|c|c|}
\hline Patients & $\begin{array}{l}\text { Age } \\
\text { years }\end{array}$ & Gender & $\begin{array}{l}\text { Duration } \\
\text { years }\end{array}$ & Peanut allergy symptoms & Severity \\
\hline 1 & 8 & female & 7 & wheezing, throat swelling & severe \\
\hline 2 & 3 & male & 2 & asthma, throat swelling, loss of voice & severe \\
\hline 3 & 5 & female & 4 & abdominal pain, systemic urticaria, throat itching & moderate \\
\hline 4 & 9 & female & 8 & urticaria, angioedema, wheezing & severe \\
\hline 5 & 4 & female & 5 & wheezing & mild \\
\hline 6 & 7 & female & 7 & angioedema & severe \\
\hline 7 & 9 & male & 9 & wheezing, angioedema & severe \\
\hline 8 & 18 & female & 19 & wheezing, angioedema & severe \\
\hline 9 & 6 & male & 5 & wheezing, angioedema & severe \\
\hline 10 & 21 & male & 20 & wheezing, angioedema & severe \\
\hline $11^{*}$ & 5 & female & 4 & urticaria, angioedema, wheezing & severe \\
\hline $12^{*}$ & 24 & male & 23 & $\begin{array}{l}\text { urticaria, angioedema, abdominal pain, vomiting, } \\
\text { diarrhea, difficulty wheezing }\end{array}$ & severe \\
\hline $13^{*}$ & 8 & male & 7 & wheezing, hypotension & severe \\
\hline $14^{*}$ & 7 & male & 6 & lip swelling, throat swelling & severe \\
\hline $15^{*}$ & 6 & male & 5 & throat swelling & severe \\
\hline 16 & 28 & female & 27 & oral food challenge & moderate \\
\hline
\end{tabular}

* These subjects were part of a phase I open-label study of omalizumab.

Table 2. Biological characteristics of the study subjects

\begin{tabular}{ccccll}
\hline Subject & $\begin{array}{l}\text { Total IgE } \\
\text { kU/l }\end{array}$ & $\begin{array}{l}\text { Cockroach- } \\
\text { specific } \\
\text { IgE, kU/l }\end{array}$ & $\begin{array}{l}\text { Allergen- } \\
\text { specific } \\
\text { IgE, kU/l }\end{array}$ & $\begin{array}{l}\text { Allergen- } \\
\text { specific } \\
\text { skin test }\end{array}$ & $\begin{array}{l}\text { Omalizumab } \\
\text { dose, mg/kg } \\
\text { per IU/ml IgE }\end{array}$ \\
\hline 1 & 591 & 2.98 & $>100(\mathrm{P})$ & $4+(\mathrm{P})$ & \\
2 & 257 & $<0.35$ & $43.6(\mathrm{C})$ & $3+(\mathrm{C})$ & \\
3 & 1,480 & ND, SK- & $>100(\mathrm{P})$ & $4+(\mathrm{P})$ & \\
4 & 180 & ND, SK- & $12.4(\mathrm{P})$ & $3+(\mathrm{P})$ & \\
5 & 126 & $<0.35$ & $0.35(\mathrm{P})$ & $3+(\mathrm{P})$ & \\
6 & 3,206 & 3.81 & $83.5(\mathrm{P})$ & $3+(\mathrm{P})$ & \\
7 & 1,975 & 5.07 & $67(\mathrm{P})$ & $4+(\mathrm{P})$ & \\
8 & 3,050 & 0.85 & $13.5(\mathrm{P})$ & $2+(\mathrm{P})$ & \\
9 & 1,752 & 0.32 & $79(\mathrm{~W})$ & $3+(\mathrm{W})$ & \\
10 & 434 & $\mathrm{ND}, \mathrm{SK}-$ & $83(\mathrm{C})$ & $4+(\mathrm{C})$ & \\
$11^{*}$ & 1,850 & 17.3 & $100(\mathrm{P})$ & $4+(\mathrm{P})$ & 0.008 \\
$12^{*}$ & 284 & $<0.35$ & $15.1(\mathrm{P})$ & $3+(\mathrm{P})$ & 0.017 \\
$13^{*}$ & 321 & 3.53 & $36.4(\mathrm{P})$ & $3+(\mathrm{P})$ & 0.02 \\
$14^{*}$ & 784 & 2.24 & $69.7(\mathrm{P})$ & $3+(\mathrm{P})$ & 0.022 \\
$15^{*}$ & 167 & 6 & $88.67(\mathrm{P})$ & $4+(\mathrm{P})$ & 0.06 \\
16 & 432 & $<0.35$ & $41(\mathrm{~A})$ & $2+(\mathrm{A})$ & \\
\hline
\end{tabular}

Specific allergens are indicated between parentheses. Skin test results were obtained as per standard methods and were judged positive as compared to a histamine control. $\mathrm{A}=$ Apple; $\mathrm{C}=\mathrm{ca}-$ shew; $\mathrm{P}=$ peanut; $\mathrm{W}=$ walnut; $\mathrm{ND}, \mathrm{SK}-=$ not done because of negative skin test. ${ }^{*}$ These subjects were part of a phase I openlabel study of omalizumab.
(San Jose, Calif., USA), and CD203c (NP4D6) from Biolegend (San Diego, Calif., USA). The gating strategy to identify basophils is illustrated in figure 1. After staining, cells were washed with excess PBS-EDTA, centrifuged $\left(490 \mathrm{~g}, 5 \mathrm{~min}, 4^{\circ} \mathrm{C}\right)$ and the supernatant was removed. Upon resuspension in $100 \mu$ l of PBS-EDTA ( $2.5 \mathrm{~mm}$ final), cells were fixed with $2 \mathrm{ml}$ of $1 \times$ Lyze/Fix PhosFlow (BD Biosciences) for $30 \mathrm{~min}$ on ice, in the dark. Then, the cells were washed once by centrifugation $\left(490 \mathrm{~g}, 5 \mathrm{~min}, 4^{\circ} \mathrm{C}\right)$ before acquisition on the flow cytometer.

Flow Cytometry Data Acquisition and Analysis

Data for 150,000-200,000 cells per sample were acquired on an LSRII digital flow cytometer equipped with 4 lasers $(535,488$, 633, $405 \mathrm{~nm}$ ), 2 light scatter detectors (yielding forward and side scatter data) and 18 fluorescent detectors (BD Biosciences). Acquisition was controlled using the DiVa software (BD Biosciences). Compensation was done using single-stained beads or cells during postacquisition analysis in the FlowJo software (Treestar, Ashland, Oreg., USA), as previously described [24, 25].

\section{Statistical Analysis}

Between- and within-group comparisons used the nonparametric Wilcoxon rank sum and signed rank tests, respectively. Pairwise correlations used the Spearman test. Predictive values of tests (such as blood basophil CD203c) for subject identification (subjects with nut allergy vs. healthy controls) were calculated by means of nominal logistic regression, yielding $\mathrm{p}$ values for negative $\log$-likelihood $\chi^{2}$ tests. Predictive abilities were expressed as the area under the receiver operating characteristics (ROC) curve [26], which plots the frequency of true positive (sensitivity) against 


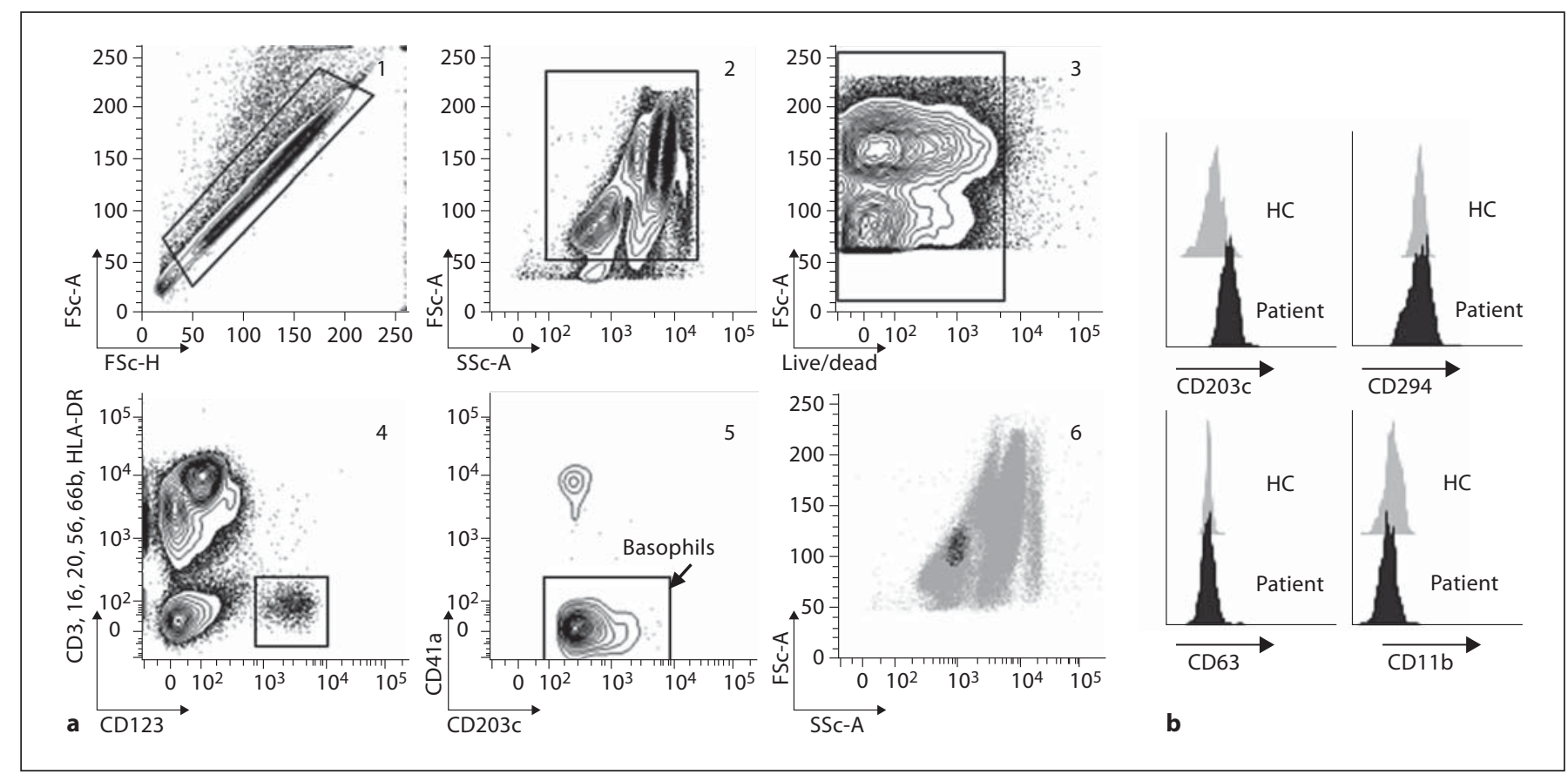

Fig. 1. Flow cytometry enables basophil phenotyping from one drop of blood. a (1) Doublets were excluded based on forward scatter area versus height; (2) leukocytes were selected based on forward and side scatter; (3) dead cells were excluded using the viability marker Live/Dead Near InfraRed; (4) basophils were selected as the CD3-/CD16-/CD20-/CD56-/CD66b-/HLA-DR- and
CD123+ population; (5) platelets were excluded using CD41a; (6) confirmation of gated basophil subset as intermediate for forward scatter and low for side scatter. b Basophil CD11b, CD63, CD203c and CD294 levels at baseline from 1 healthy control (HC) and 1 subject with peanut allergy. the frequency of false positive ( 1 - specificity) results. Area values were considered excellent at more than 0.9 (1.0 is the maximal). Differences or correlations were considered significant at a $\mathrm{p}$ value of less than 0.05 .

\section{Results}

\section{Basophil CD203c Levels Are Increased at Baseline in} Subjects with Nut Allergy

We used flow cytometry and sequential gating methods to discriminate live basophils from cell clumps (cells that are bound to each other and cannot be characterized individually) [27], dead cells, platelets and platelet-leukocyte aggregates and nonbasophil leukocytes in peripheral blood samples (fig. 1). Basophils represent approximately $0.5 \%$ of the leukocyte population in peripheral blood. We found that basophil CD203c levels at baseline (measured as median fluorescence intensity, MFI) were significantly increased in subjects with nut allergy compared to healthy controls (fig. 2; 13 in each group, $p<$

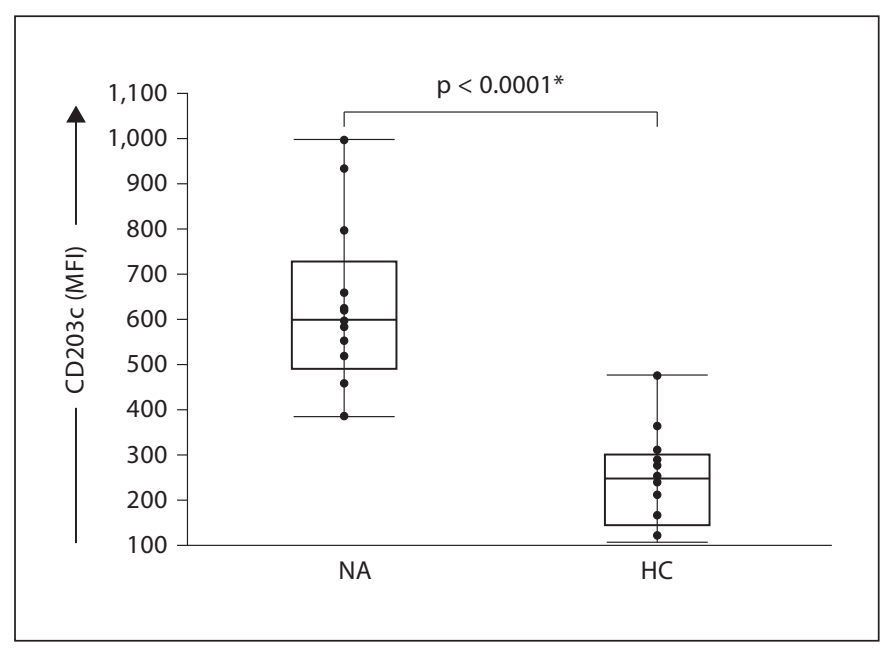

Fig. 2. Predictive value of basophil CD203c levels at baseline for the clinical classification of subjects with nut allergy. Basophil CD203c levels at baseline were significantly increased in subjects with nut allergy (NA) compared to healthy controls (HC), $n=13$ in each group, $\mathrm{p}<10^{-4}$. Statistical significance was assessed by Wilcoxon rank sum nonparametric test. Each point represents a single sample. 


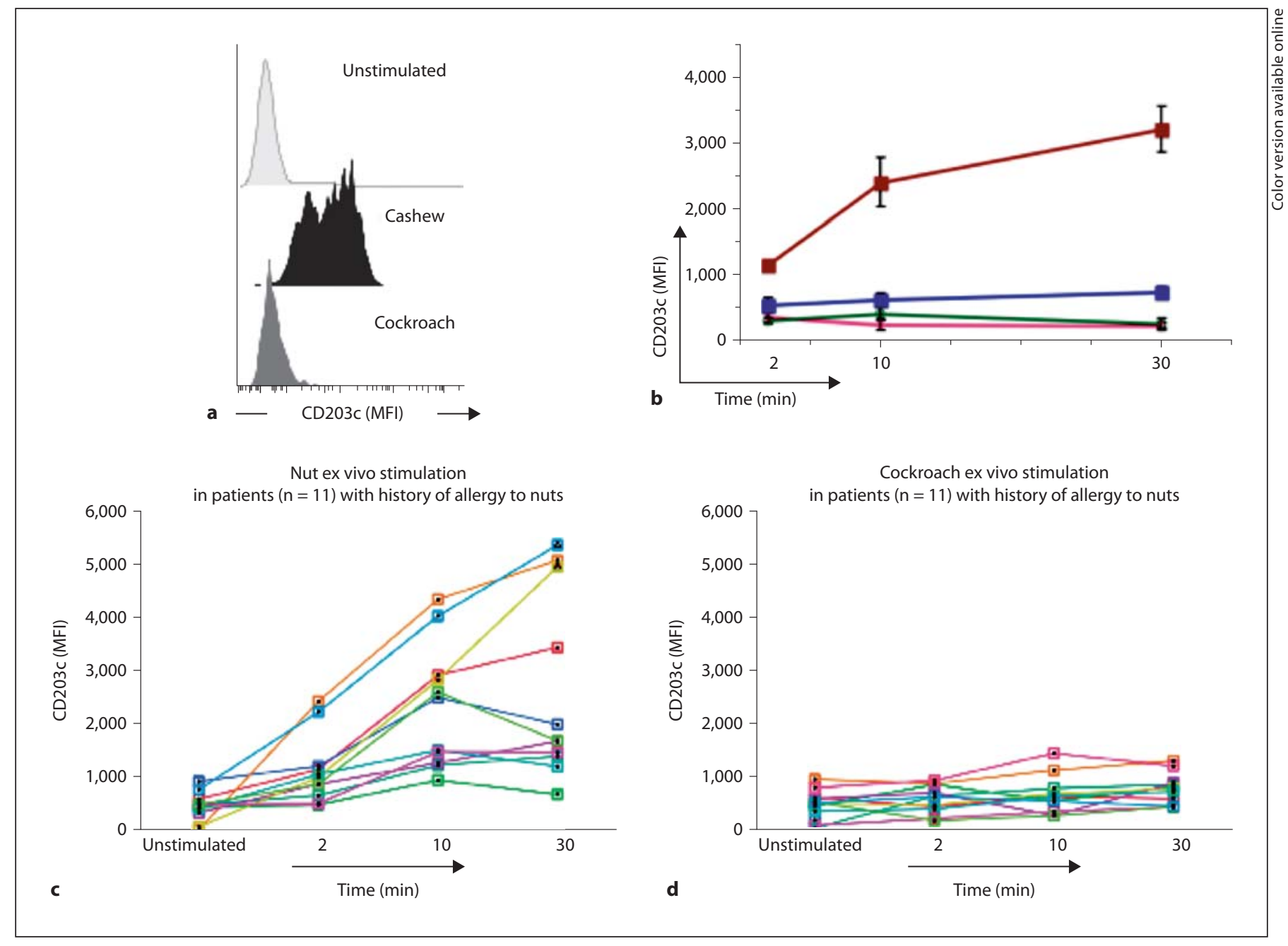

Fig. 3. Ex vivo stimulation with nut allergen further increases basophil CD203c levels in subjects with nut allergy. a Basophils in the sample from a single subject stimulated with the offending allergen (cashew) showed increased CD203c expression, some clustering in a CD203c $\mathrm{c}^{\text {hi }}$ peak (bimodal distribution); b time course analysis (2-, 10- and 30-min stimulations) showing group means and standard errors for basophil CD203c levels (MFI) from

healthy controls $(n=8)$ stimulated with peanut (pink line) or cockroach (green line) allergens, compared to subjects with nut allergy $(n=11)$ stimulated with nut ( 10 with peanut, 1 with cashew) (red line) or cockroach (blue line) allergens. In c and d, we represent basophil CD203c levels (MFI) as measured from the same individual subjects, each indicated by a line of a different color, upon stimulation with nut (c) or cockroach (d) allergens.

0.0001). Baseline levels for the other activation markers tested, that is, CD11b, CD63, CD123 and CD294, were not different between these two groups (online suppl. fig. 1). Consistent with the limited overlap between the relative distributions of values in subjects with nut allergy compared to healthy controls (fig. 2), basophil CD203c levels at baseline yielded a statistically predictive value between the two groups (area under the ROC curve $=0.96,13$ in each group, $\left.\mathrm{p}<10^{-4}\right)$.

Ex vivo Nut Allergen Stimulation Further Increases Basophil CD203c Levels in Subjects with Nut Allergy We confirmed the work of others in observing an upregulation of blood basophil CD203c levels after stimulation with the offending allergen (peanut, cashew or walnut) $[9,13-19]$. Basophils in an unstimulated blood sample were mostly CD203c ${ }^{\text {lo }}$; by contrast, a sizeable fraction of basophils in ex vivo stimulated samples showed increased CD203c expression and became CD203c ${ }^{\text {hi }}$ (fig. 3a). Quantitatively, this shift was reflected by an in- 
crease in CD203c MFI (fig. 3) which was $>8$ fold higher in basophils from subjects with nut allergy than in basophils from healthy controls stimulated with the same nut allergen (fig. $3 ; \mathrm{p}<0.003$ ). Basophils from subjects with nut allergy exhibited significantly higher responses to the specific offending nut allergen than to an aeroallergen (cockroach) to which they had no history of allergy (fig. 3; $\mathrm{n}=11$; nut vs. cockroach allergen stimulation: $2-, 4-$ and 5-fold differences, in CD203c MFI increases after 2-, 10 and 30-minute stimulations, respectively; $\mathrm{p}<0.002$, $\mathrm{p}<$ 0.0008 and $\mathrm{p}<0.003$ ). Additionally, we confirmed that there was no increase in basophil CD203c levels when the stimulation occurred with a nonoffending, nut allergen (for example, cashew for a subject with peanut allergy, or vice versa; online suppl. fig. 2). Altogether, our results establish this method as a rapid, specific, ex vivo assay for detecting allergic predisposition to specific nut allergens in human subjects.

\section{CD203c Provides a More Efficient and Reliable Index}

of Nut Allergy than Other Basophil Surface Markers

CD63 levels have been previously reported to be increased on basophils from allergic subjects in response to stimulation with offending allergens $[13,19]$. However, in our study, CD63 expression was not a reliable endpoint in that its levels increased on basophils in 11 of the 13 subjects tested, whereas increased levels of CD203c were detected in all 13. Moreover, in the 13 subjects tested, following ex vivo stimulation with nut allergen, the percentage of increase in MFI for CD63 was significantly lower than that for CD203 (online suppl. fig. 3b). Basophils from subjects with allergy to a specific nut allergen exhibited higher responses to this allergen than to an aeroallergen (cockroach) to which they had no relevant history of clinical allergy (online suppl. fig. $3 \mathrm{a} ; \mathrm{n}=11$; nut vs. cockroach allergen challenge: 2 - and 3.5-fold increases, respectively, in CD63 expression after 10- or/and 30-min stimulation with each of the allergens; $\mathrm{p}<0.028$ or $\mathrm{p}<$ 0.032 , respectively). However, no increase in basophil CD63 levels was detected in our assay at $2 \mathrm{~min}$. Other basophil markers tested (CD11b, CD123, CD294) were not significantly increased by nut allergen exposure at any of the 3 time points analyzed (data not shown).

\section{Blood Basophil CD203c Levels at Baseline and upon} ex vivo Stimulation Are Largely Independent of

Plasma IgE and Other Plasma Factors

Total IgE levels in plasma are a common indicator of allergic predisposition. Here, we found that total IgE levels in plasma from subjects with nut allergy at baseline did not correlate with basophil CD203c levels at baseline, nor did they predict CD203c levels upon 2 or 30 min of ex vivo stimulation with the offending nut allergen. However, a significant correlation existed between total IgE levels in plasma at baseline and basophil CD203c levels upon 10 min of ex vivo stimulation with the offending nut allergen $(\mathrm{n}=15$, Spearman rho $=0.554, \mathrm{p}<0.0396)$. It is known that IgE is strongly bound to basophil FceRI and will remain bound even if plasma is removed from the cells and cells are subsequently placed in PBS. When we replaced subject plasma by PBS during the procedure, we found that the increase in basophil CD203c levels upon allergen stimulation still occurred (online suppl. fig. 4).

\section{Basophil CD203c Expression at Baseline and following Stimulation with Nut Allergen Is Significantly Decreased during Omalizumab Treatment but Returns to Pretreatment Levels after Treatment Cessation}

Longitudinal studies of basophil CD203c levels at baseline in our cohort of omalizumab-treated subjects with peanut allergy (tables 1,2$)$ demonstrated a significant decrease at 4 and 8 weeks of treatment $(\mathrm{p}<0.05$ for pretreatment vs. 4 weeks; for 4 weeks vs. 8 weeks and for pretreatment vs. 8 weeks after $30 \mathrm{~min}$ of ex vivo stimulation) (fig. 4a). Importantly, baseline basophil CD203clevels tended to increase 1 month after cessation of treatment. Furthermore, we show that the increase in basophil CD203c levels upon ex vivo stimulation with peanut allergen was significantly lowered during omalizumab treatment (fig. 4c; $p<0.033$ at either 4 or 8 weeks of omalizumab treatment vs. pretreatment, $n=5$ ). The abrogation of the allergen-induced increase in basophil CD203c levels seems to be temporary ( $p<0.07$ for comparison of pre-therapy vs. post-therapy levels of CD203c). One month after cessation of omalizumab treatment, we observed an increase in basophil CD203c levels upon ex vivo stimulation with peanut allergen after 2, 10 and 30 min of ex vivo stimulation (fig. 4b). Reduced levels of CD63 were observed at (1) the 10 -min time points, between pretreatment and both 4 or 8 weeks of omalizumab treatment (online suppl. fig. 5b; $p<0.039$ at both 4 and 8 weeks of omalizumab treatment vs. pre-treatment, $\mathrm{n}=5$ ) and (2) at the 30-min time points, between only pre-treatment and 8 weeks of omalizumab treatment (online suppl. fig. $5 b ; p<0.041$ at 8 weeks of omalizumab treatment vs. pre-treatment, $n=5$ ). By one month after cessation of omalizumab treatment, the recovery of baseline basophil CD63 levels was marginal (online suppl. fig. 5a, b). We also measured the levels of free IgE (non-omalizumab 


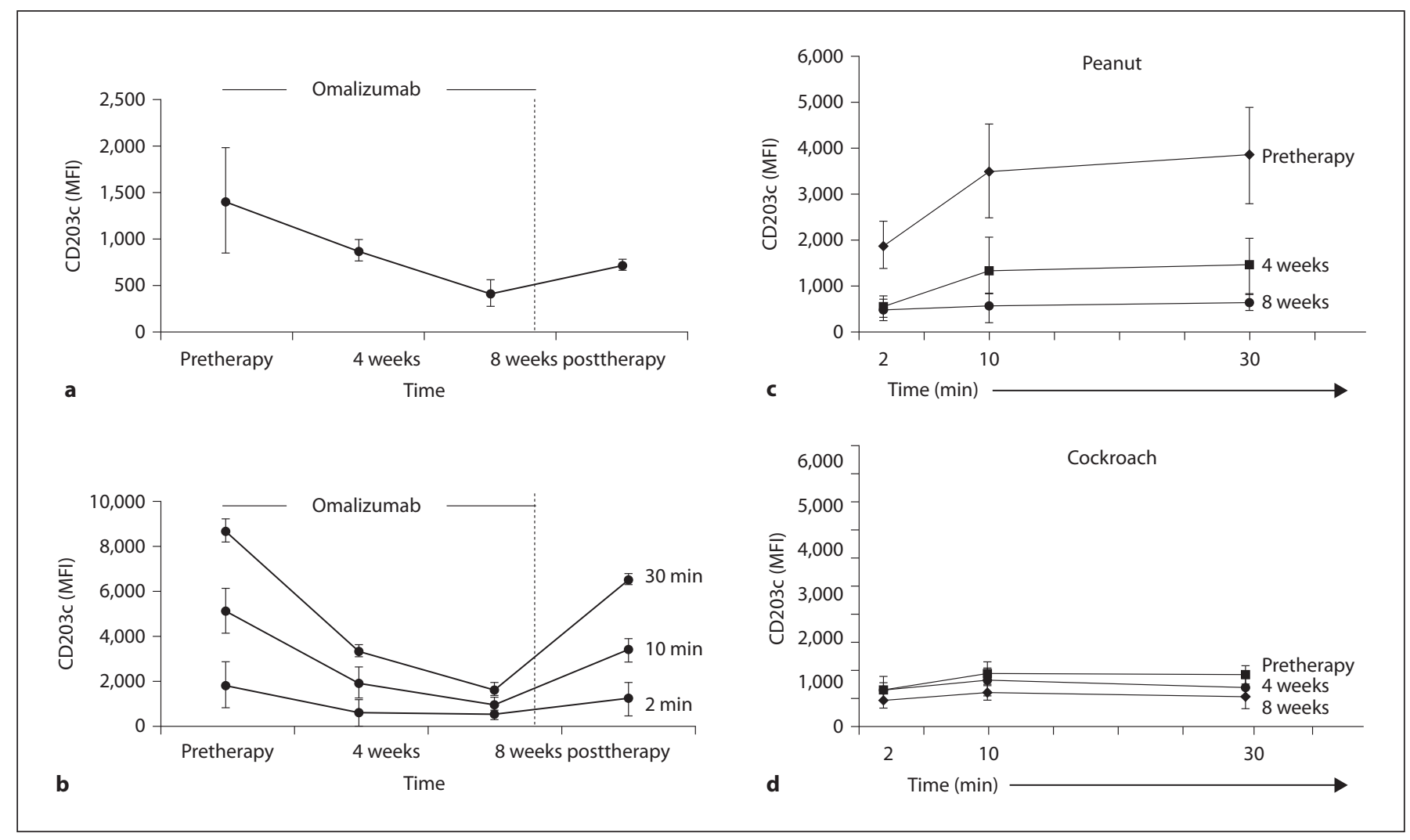

Fig. 4. Levels of basophil CD203c expression at baseline and following stimulation with peanut allergen are significantly decreased during omalizumab treatment but return to pretreatment levels after treatment cessation. a Basophil CD203c levels at baseline measured before omalizumab treatment, during treatment (4 and 8 weeks) and 4 weeks after treatment cessation. b Basophil CD203c levels following ex vivo stimulation (2-, 10- and 30-min stimulations) with peanut measured before omalizumab treat-

bound) in the cohort of omalizumab-treated subjects (pretreatment vs. on treatment). The level of free $\operatorname{IgE}$ was decreased in 4 of the 5 subjects tested (online suppl. table 1).

\section{Discussion}

Several groups have analyzed the expression of various basophil surface structures in an effort to develop new diagnostic and prognostic indicators of allergy [9, 13-19]. Here, we report that basophil CD203c levels are increased at baseline in a cohort of subjects with nut allergy compared to healthy controls, suggesting that basophils may be in a 'primed' state in such allergic subjects. In addition to demonstrating this baseline difference, our studies ment, during treatment (4 and 8 weeks) and 4 weeks after treatment cessation. The figure represents the group means and standard errors for basophil CD203c levels (MFI) from peanut allergic subjects $(\mathrm{n}=5)$ stimulated with peanut allergen. $\mathbf{c}$, d Comparative data for basophil CD203c levels following ex vivo stimulation of subjects with peanut allergy with peanut allergen (c) or cockroach allergen (d) before omalizumab treatment and during treatment (4 and 8 weeks).

confirmed previous reports demonstrating that basophil CD203c levels increase upon ex vivo stimulation with the allergen to which the subject is sensitive and that this response can be detected rapidly $[9,17]$. Allergen-induced increases in basophil CD203c levels proceeded equally well when the basophils were tested either in absence or presence of the subject's plasma. Finally, in 5 subjects with peanut allergy, basophil CD203c levels at baseline were decreased and their increase upon ex vivo stimulation with peanut allergen was reduced after 4 and 8 weeks of omalizumab treatment but returned toward pretreatment levels after cessation of treatment.

Our study shows that measuring baseline levels of basophil CD203c directly (that is, without any cell separation or activation) in whole blood can effectively discriminate between subjects with nut allergy and healthy con- 
trols. CD203c is a transmembrane molecule that belongs to the family of ectonucleotide pyrophosphatases/phosphodiesterases [28]; it has been reported that this is the only surface antigen which, among hematopoietic cells, is specifically expressed at baseline by basophils and mast cells in healthy subjects (and CD34+ progenitor cells) [9]. While further work will be required to establish the mechanisms which account for the increased levels of surface CD203c on basophils in nut-allergic subjects, it is interesting to note that the promoter region of the CD203c gene contains binding sites for three critical transcription factors which may be activated in basophils from allergic subjects. For example, basophils from allergic subjects can be chronically exposed to IL-3 [27], which mediates its function via the transcription factor cyclic AMP-response element binding protein 1 [29]. Alternatively, basophil exposure to IgE [30-32] leads to activation of the Syk tyrosine kinase, downstream of FceRI ligation. Syk then activates the transcription factors Ets like gene1 [33] and activation transcription factor 2 [34]. A better understanding of these signaling cascades might lead to the discovery of additional biomarkers and/or targets for therapy in allergic subjects.

Further work will be needed to extend this analysis and examine baseline levels of basophil CD203c in whole blood from subjects with aeroallergen allergies. Based on the current literature, it seems unlikely that a similar elevation of basophil CD203c will be found in subjects with aeroallergen allergy, since such allergens are generally known to be less likely to cause basophil priming and anaphylaxis than nut allergens. That said, to our knowledge, most of the research in this area has focused on changes in levels of expression of basophil CD203c following ex vivo stimulation with the offending allergen $[10,15,16,35]$. In patients who received rush immunotherapy for Japanese cedar pollinosis, the authors observed a reduction in CD203c expression after the therapy, suggesting the utility of the basophil CD203c level for monitoring immunotherapy $[15,16]$. Interestingly, baseline basophil CD203c levels have also been found to be upregulated in subjects with chronic urticaria [36].

The ex vivo activation of basophils and upregulation of their CD203c occurred in whole blood reconstituted with autologous platelet-free plasma (from the original EDTA-containing tube). We found that CD203c upregulation also occurred when the autologous platelet-poor plasma (less than $10 \%$ of platelets were left) was replaced by regular PBS (without either EDTA or calcium). Thus, in our hands, increases in basophil CD203c (and CD63) upon ex vivo basophil activation with specific antigen did not require exogenous calcium, indicating that intracellular calcium stores were sufficient to promote basophil activation upon antigen binding in this setting, as has also been observed in other studies [15, 16, 35, 37-40]. However, it is possible that the relatively weak CD63 basophil response following ex vivo stimulation with an offending allergen reflected, at least in part, the use of experimental conditions that were not optimal for induction of basophil degranulation (that is, there was no extracellular calcium in the medium used).

Other studies have shown increased levels of CD203c on blood basophils upon exposure to pollen, wheat or cat allergens ex vivo [9, 13-19], or increased levels of CD63 on basophils exposed to peanut, wheat, milk, egg, cedar pollen or amoxicillin $[13,16,17,19,40]$. When we compared CD203c to CD63, our results were most consistent with those of Ocmant et al. [38], in that CD203c represented a more reliable marker of basophil activation. However, in a recent study of subjects with milk allergy, changes in basophil CD63 levels upon ex vivo stimulation were more pronounced than those of CD203c [19]. Taken together, results from our group and others suggest that it may be useful to assess levels of both CD63 and CD203c on basophils; while both markers can be increased upon basophil stimulation, these two markers may be modulated with different kinetics, perhaps reflecting different mechanisms for their mobilization, or may be differentially activated based on the composition of the medium used to perform the test.

In our study, basophil CD203c levels were decreased at baseline, and their increase upon ex vivo stimulation with peanut allergen was reduced after 4 and 8 weeks of omalizumab treatment but returned toward pretreatment levels after treatment cessation. These findings suggest a potential clinical relevance for the method described here (that is, obtaining blood basophil CD203c measurements at baseline followed by ex vivo stimulation with an offending allergen). Omalizumab is a humanized

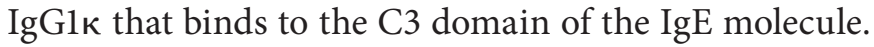
This binding prevents IgE ligation to its receptors, including FceRI $\alpha$, on effector cells. Omalizumab has been shown to downregulate surface expression of FceRI $\alpha$ on basophils after 2 weeks of therapy, presumably because of its ability to reduce levels of free IgE [31, 41]. Basophils from allergic subjects treated with omalizumab can exhibit reduced activation for degranulation and mediator release in vitro when exposed to antigens to which the subject is sensitive, again presumably reflecting the reduced expression of FceRI in these cells compared to baseline values [42]. In light of those findings, we are not 
surprised that basophils from omalizumab-treated subjects also exhibit reduced IgE- and antigen-dependent increases in surface CD203c.

In summary, basophils from subjects with nut allergy exhibit increased surface levels of CD203c at baseline and following rapid ex vivo stimulation with nut allergen. Both can be reduced by omalizumab therapy. These results suggest that basophil CD203c levels can be used for baseline diagnosis and therapeutic monitoring in subjects with nut allergy. The assay described here might also be useful for the clinical monitoring of subjects who undergo omalizumab therapy for other food allergies. Finally, it is possible that the rapid measurement of basophil CD203c levels in whole blood, as performed here, can be used as an in vitro screening method to identify agents which inhibit basophil activation and as an ex vivo outcome measure to test the efficacy of new anti-allergy treatments.

\section{Acknowledgments}

We thank our subjects for their participation. All free IgE measurements were performed at Johns Hopkins University (Hamilton Laboratory). We also thank Drs. R. Moss and J. Faix for their review of the manuscript, C. Crumpton and J. Van Dyke at the Stanford FACS Facility, Drs. M. Makam, E. Engleman, K. Atkuri and P. Ngatchou-Sadate for critical advice, and E. Hoyte, D. Robinson and M. Becard for technical assistance.

We would like to thank: Stanford School of Medicine's Dean Fellowship (Y.G.) and the Stanford Institute of Immunity, Transplantation and Infectious Diseases Seed Grant (K.C.N.), Orsak Family Fund (K.C.N.), Lucile Packard Children's Hospital Children's Health Research Program (Y.G. and K.C.N.), ARARD (Association Régionale d'Assistance Respiratoire à Domicile) (Y.G.), Skippy Frank Foundation (R.T. and Y.G.), and United States Public Health Service grants AI23990, AI070813 and CA72074 (M.T. and S.J.G.).

\section{References}

-1 Burks AW: Peanut allergy. Lancet 2008;371: 1538-1546.

-2 Sicherer SH, Sampson HA: 9. Food allergy. J Allergy Clin Immunol 2006;117:S470-S475.

-3 Cox L, Williams B, Sicherer S, Oppenheimer J, Sher L, Hamilton R, Golden D: Pearls and pitfalls of allergy diagnostic testing: report from the American College of Allergy, Asthma and Immunology/American Academy of Allergy, Asthma and Immunology Specific IgE Test Task Force. Ann Allergy Asthma Immunol 2008;101:580-592.

4 Clark AT, Islam S, King Y, Deighton J, Anagnostou K, Ewan PW: Successful oral tolerance induction in severe peanut allergy. Allergy 2009;64:1218-1220.

5 Jones SM, Pons L, Roberts JL, Scurlock AM, Perry TT, Kulis M, Shreffler WG, Steele P, Henry KA, Adair M, Francis JM, Durham S, Vickery BP, Zhong X, Burks AW: Clinical efficacy and immune regulation with peanut oral immunotherapy. J Allergy Clin Immunol 2009;124:292-300, 300, e291-e297.

6 Leung DY, Sampson HA, Yunginger JW, Burks AW Jr, Schneider LC, Wortel CH, Davis FM, Hyun JD, Shanahan WR Jr: Effect of anti-IgE therapy in patients with peanut allergy. N Engl J Med 2003;348:986-993.

7 Hamilton RG, Marcotte GV, Saini SS: Immunological methods for quantifying free and total serum IgE levels in allergy patients receiving omalizumab (xolair) therapy. J Immunol Methods 2005;303:81-91.

$\checkmark 8$ MacGlashan D Jr: Therapeutic efficacy of omalizumab. J Allergy Clin Immunol 2009; 123:114-115.
9 Buhring HJ, Streble A, Valent P: The basophil-specific ectoenzyme e-npp3 (cd203c) as a marker for cell activation and allergy diagnosis. Int Arch Allergy Immunol 2004;133: 317-329.

10 Aerts NE, Dombrecht EJ, Bridts CH, Hagendorens MM, de Clerck LS, Stevens WJ, Ebo DG: Simultaneous flow cytometric detection of basophil activation marker cd63 and intracellular phosphorylated p38 mitogen-activated protein kinase in birch pollen allergy. Cytometry B Clin Cytom 2008;76B:8-17.

11 Kleine-Tebbe J, Erdmann S, Knol EF, MacGlashan DW Jr, Poulsen LK, Gibbs BF: Diagnostic tests based on human basophils: potentials, pitfalls and perspectives. Int Arch Allergy Immunol 2006;141:79-90.

12 Simons FE, Frew AJ, Ansotegui IJ, Bochner BS, Golden DB, Finkelman FD, Leung DY, Lotvall J, Marone G, Metcalfe DD, Muller U, Rosenwasser LJ, Sampson HA, Schwartz LB, van Hage M, Walls AF: Practical Allergy (PRACTALL) report: risk assessment in anaphylaxis. Allergy 2008;63:35-37.

13 Abuaf N, Rostane H, Rajoely B, Gaouar H, Autegarden JE, Leynadier F, Girot R: Comparison of two basophil activation markers CD63 and CD203C in the diagnosis of amoxicillin allergy. Clin Exp Allergy 2008;38:921928.

14 de Weck AL, Sanz ML, Gamboa PM, Aberer W, Bienvenu J, Blanca M, Demoly P, Ebo DG, Mayorga L, Monneret G, Sainte-Laudy J: Diagnostic tests based on human basophils: more potentials and perspectives than pitfalls. Int Arch Allergy Immunol 2008; 146: 177-189.
15 Fujisawa T, Nagao M, Hiraguchi Y, Hosoki K, Tokuda R, Usui S, Masuda S, Shinoda M, Hashiguchi A, Yamaguchi M: Biomarkers for allergen immunotherapy in cedar pollinosis. Allergol Int 2009;58:163-170.

16 Nagao M, Hiraguchi Y, Hosoki K, Tokuda R, Usui T, Masuda S, Yamaguchi M, Fujisawa T: Allergen-induced basophil CD203c expression as a biomarker for rush immunotherapy in patients with japanese cedar pollinosis. Int Arch Allergy Immunol 2008;146(suppl 1):47-53.

17 Ocmant A, Mulier S, Hanssens L, Goldman M, Casimir G, Mascart F, Schandene L: Basophil activation tests for the diagnosis of food allergy in children. Clin Exp Allergy 2009;39:1234-1245.

18 Tokuda R, Nagao M, Hiraguchi Y, Hosoki K, Matsuda T, Kouno K, Morita E, Fujisawa T: Antigen-induced expression of CD203c on basophils predicts IgE-mediated wheat allergy. Allergol Int 2009;58:193-199.

19 Wanich N, Nowak-Wegrzyn A, Sampson HA, Shreffler WG: Allergen-specific basophil suppression associated with clinical tolerance in patients with milk allergy. J Allergy Clin Immunol 2009;123:789-794, e720.

20 Nowak-Wegrzyn A, Assa’ad AH, Bahna SL, Bock SA, Sicherer SH, Teuber SS: Work group report: oral food challenge testing. J Allergy Clin Immunol 2009;123:S365-S383.

21 Gibbs BF, Plath KE, Wolff HH, Grabbe J: Regulation of mediator secretion in human basophils by $\mathrm{p} 38$ mitogen-activated protein kinase: phosphorylation is sensitive to the effects of phosphatidylinositol 3-kinase inhibitors and calcium mobilization. J Leukoc Biol 2002;72:391-400. 
-22 Miller RL, Eppinger TM, McConnell D, Cunningham-Rundles C, Rothman P: Analysis of cytokine signaling in patients with extrinsic asthma and hyperimmunoglobulin E. J Allergy Clin Immunol 1998;102:503511.

-23 Hamilton RG, Franklin Adkinson N Jr: In vitro assays for the diagnosis of IgE-mediated disorders. J Allergy Clin Immunol 2004; 114:213-225; quiz 226.

24 Herzenberg LA: FACS innovation: a view from Stanford. Clin Invest Med 2004;27: 240-252.

-25 Tung JW, Heydari K, Tirouvanziam R, Sahaf B, Parks DR, Herzenberg LA: Modern flow cytometry: a practical approach. Clin Lab Med 2007;27:453-468, v.

-26 DeLong ER, DeLong DM, Clarke-Pearson DL: Comparing the areas under two or more correlated receiver operating characteristic curves: a nonparametric approach. Biometrics 1988;44:837-845.

-27 Ghosn EE, Yang Y, Tung J, Herzenberg LA: CD11b expression distinguishes sequential stages of peritoneal b-1 development. Proc Natl Acad Sci USA 2008;105:5195-5200.

-28 Buhring HJ, Seiffert M, Giesert C, Marxer A, Kanz L, Valent P, Sano K: The basophil activation marker defined by antibody $97 \mathrm{a} 6$ is identical to the ectonucleotide pyrophosphatase/phosphodiesterase 3. Blood 2001;97: 3303-3305.

-29 Gubina E, Luo X, Kwon E, Sakamoto K, Shi YF, Mufson RA: Betac cytokine receptor-induced stimulation of camp response element binding protein phosphorylation requires protein kinase $\mathrm{c}$ in myeloid cells: a novel cytokine signal transduction cascade. J Immunol 2001;167:4303-4310.
30 Didichenko SA, Spiegl N, Brunner T, Dahinden CA: IL-3 induces a PIM1-dependent antiapoptotic pathway in primary human basophils. Blood 2008;112:3949-3958.

31 MacGlashan D Jr, Lichtenstein LM, McKenzie-White J, Chichester K, Henry AJ, Sutton BJ, Gould HJ: Upregulation of FC $\varepsilon$ RI on human basophils by IgE antibody is mediated by interaction of IgE with FCeRI. J Allergy Clin Immunol 1999;104:492-498.

32 Park BL, Kim LH, Choi YH, Lee JH, Rhim T, Lee YM, Uh ST, Park HS, Choi BW, Hong SJ, Park CS, Shin HD: Interleukin 3 (IL3) polymorphisms associated with decreased risk of asthma and atopy. J Hum Genet 2004;49: 517-527.

-33 Bhoumik A, Ronai Z: ATF2: a transcription factor that elicits oncogenic or tumor suppressor activities. Cell Cycle 2008;7:23412345.

34 Shore P, Bisset L, Lakey J, Waltho JP, Virden $\mathrm{R}$, Sharrocks AD: Characterization of the ELK-1 ETS DNA-binding domain. J Biol Chem 1995;270:5805-5811.

35 Ebo DG, Bridts CH, Hagendorens MM, Aerts NE, De Clerck LS, Stevens WJ: Basophil activation test by flow cytometry: present and future applications in allergology. Cytometry B Clin Cytom 2008;74:201-210.

36 Yasnowsky KM, Dreskin SC, Efaw B, Schoen D, Vedanthan PK, Alam R, Harbeck RJ: Chronic urticaria sera increase basophil CD203c expression. J Allergy Clin Immunol 2006;117:1430-1434.
37 Chirumbolo S, Conforti A, Ortolani R, Vella A, Marzotto M, Bellavite P: Stimulus-specific regulation of CD63 and $\mathrm{CD} 203 \mathrm{c}$ membrane expression in human basophils by the flavonoid quercetin. Int Immunopharmacol 2010;10:183-192.

38 Ocmant A, Peignois Y, Mulier S, Hanssens L, Michils A, Schandene L: Flow cytometry for basophil activation markers: the measurement of CD203c up-regulation is as reliable as CD63 expression in the diagnosis of cat allergy. J Immunol Methods 2007;320:4048.

39 Ono E, Taniguchi M, Higashi N, Mita H, Kajiwara K, Yamaguchi H, Tatsuno S, Fukutomi Y, Tanimoto $\mathrm{H}$, Sekiya K, Oshikata C, Tsuburai T, Tsurikisawa N, Otomo M, Maeda Y, Hasegawa M, Miyazaki E, Kumamoto T, Akiyama K: CD203c expression on human basophils is associated with asthma exacerbation. J Allergy Clin Immunol 2010;125: 483-489, e483.

40 Tokuda R, Nagao M, Hiraguchi Y, Hosoki K, Matsuda T, Kouno K, Morita E, Fujisawa T: Antigen-induced expression of CD203c on basophils predicts IgE-mediated wheat allergy. Allergol Int 2009;58:193-199.

-41 Asai K, Kitaura J, Kawakami Y, Yamagata N, Tsai M, Carbone DP, Liu FT, Galli SJ, Kawakami T: Regulation of mast cell survival by IgE. Immunity 2001;14:791-800.

-42 MacGlashan DW Jr, Bochner BS, Adelman DC, Jardieu PM, Togias A, McKenzie-White J, Sterbinsky SA, Hamilton RG, Lichtenstein LM: Down-regulation of FCERI expression on human basophils during in vivo treatment of atopic patients with anti-IgE antibody. J Immunol 1997;158:1438-1445. 